\title{
Research on the Unsteady Discharge Flow of Dry Chemical Powder Tank
}

\author{
HeeGeun Song ${ }^{1}$, Junhyo Kim², Jungpil Noh ${ }^{3}$, Sunchul Huh ${ }^{4}$, Byeongkeun $\mathrm{Choi}^{5}$, \\ Hanshik Chung ${ }^{6}$, *Hyomin Jeong ${ }^{7}$ \\ ${ }^{1}$ Department of Energy and Mechanical Engineering, Gyeongsang National University, Cheondaegukchi-Gil 38, Tongyeong, \\ Gyeongnam, 650-160, South Korea \\ ${ }^{2}$ Department of Marine Engineering, Mokpo National maritime University, 61 dorim-ri, 1666 Yeongsan-ro, Cheonggye- \\ myeon, Muan-gun, Jeonnam, South Korea \\ 3,4,5,6,7 Department of Energy and Mechanical Engineering, Gyeongsang National University. Institute of Marine Industry, \\ Cheondaegukchi-Gil 38, Tongyeong, Gyeongnam, 650-160, South Korea
}

\begin{abstract}
In this study, we investigated the activation of powders by the supply of $\mathrm{N}_{2}$ gas in the dry chemical powder tanks. In this study, we investigated the effect of $\mathrm{N}_{2}$ gas on the activation of dry chemical powder $\left(\mathrm{KHCO}_{3}\right)$ in Dry chemical Powder Tank, We studied how dry chemical powder $\left(\mathrm{KHCO}_{3}\right)$ is activated according to the number of nozzles in the tank. $170 \mathrm{~kg}$, and $3000 \mathrm{~kg}$ models, the number of nozzles was 4, 8. We gave the points to confirm the activation of the powder. This study describes the optimal conditions for activation depending on the type of dry chemical powder tank and the number of nozzles.
\end{abstract}

Keywords-Powder activation, Discharge Flow, Dry Chemical Powder Tank, nitrogen gas.

\section{INTRODUCTION}

According to the "Marine Accident Statistics" at the Maritime Tribunal, the number of ship fires and explosions in the Republic of Korea is 465 cases (2011 2015) for 5 years, accounting for about $6 \%$ of all marine casualties. Among them, the oil tanker fire and explosion accident accounted for $8 \%$ of the total of 256 cases [1]. Generally, half of ship fire accidents are reported to occur in the engine room. In case of an accident, it is difficult to receive support for fire suppression from the land, and therefore, many lives and property are lost [2].

The Powder fire extinguishing system is a fire extinguishing system that suppresses fire which is less effective by water extinguishing method such as sprinkling water or scattered water and combustible gas or oil with the risk of fire spreading. The powder fire extinguishing system is a device that injects $\mathrm{N}_{2}$ gas filled in $\mathrm{N}_{2}$ cylinder into powder tank, push powder fire extinguishing agent into $\mathrm{N}_{2}$ gas pressure in powder tank and spray fire extinguishing agent in fire area. The principle of extinguishing the powder absorbs heat from the fire by the rapid endothermic reaction of the powder which is released in the place where the fire occurs. As the volume of the non-combustible powder expands, the powder covers the fire and blocks the supply of oxygen, thereby suppressing the fire.

The powder fire extinguishing system is suitable for the extinguishing of large-scale flammable gas fires and is suitable for the fire extinguishing of liquefied natural gas carrier (LNGC), liquefied petroleum gas carrier (LPGC), liquefied natural gas floating production storage facility (FLNG) ), Drillships, and gas and marine plant facilities. Powder in Dry Powder Tank mixed well with $\mathrm{N}_{2}$ gas in case of fire suppression needs to be maintained after optimal activation.

In this study, we have investigated the activation of powders in accordance with the supply of $\mathrm{N}_{2}$ gas in the dry powder tank and studied how the powder is activated according to the number of nozzles in the dry powder tank.

\section{EQUATIONS AND MATHEMATICS}

The volume fraction equation, turbulent kinetic energy and flow equation applied to the calculation are as follows[3-5].

The volume fraction equation is as follows.

$$
\frac{\alpha_{q}^{n+1} \rho_{q}^{n+1}-\alpha_{q}^{n} \rho_{q}^{n}}{\Delta t} V+\sum_{f}\left(\rho_{q}^{n+1} U_{f}^{n+1} \alpha_{q, f}^{n+1}\right)=\left[s_{\alpha_{q}}+\sum_{p=1}^{n}\left(\dot{m}_{p q}-\dot{m}_{q p}\right)\right] V
$$

The turbulent kinetic energy $\mathrm{k}$ is as follows.

$$
\frac{\partial(\rho k)}{\partial t}+\frac{\partial\left(\rho k u_{i}\right)}{\partial x_{i}}=\frac{\partial}{\partial x_{j}}\left[\frac{\mu_{t}}{\sigma_{k}} \frac{\partial k}{\partial x_{j}}\right]+2 \mu_{t} E_{i j} E_{i j}-\rho \epsilon
$$




\section{CALCUlation Condition}

\subsection{Preparation condition}

The fluid analysis and the activation analysis of the powder were carried out for $170 \mathrm{~kg}$ and $3000 \mathrm{~kg}$ dry powder tanks. The number of nozzles was set to 4 and 8 for each model. The inlet consists of two pipes, and the outlet consists of one pipe (Figure 1). Two thin pipes come in with nitrogen gas and nozzles at their ends. And the activated powder is discharged into a thick pipe.
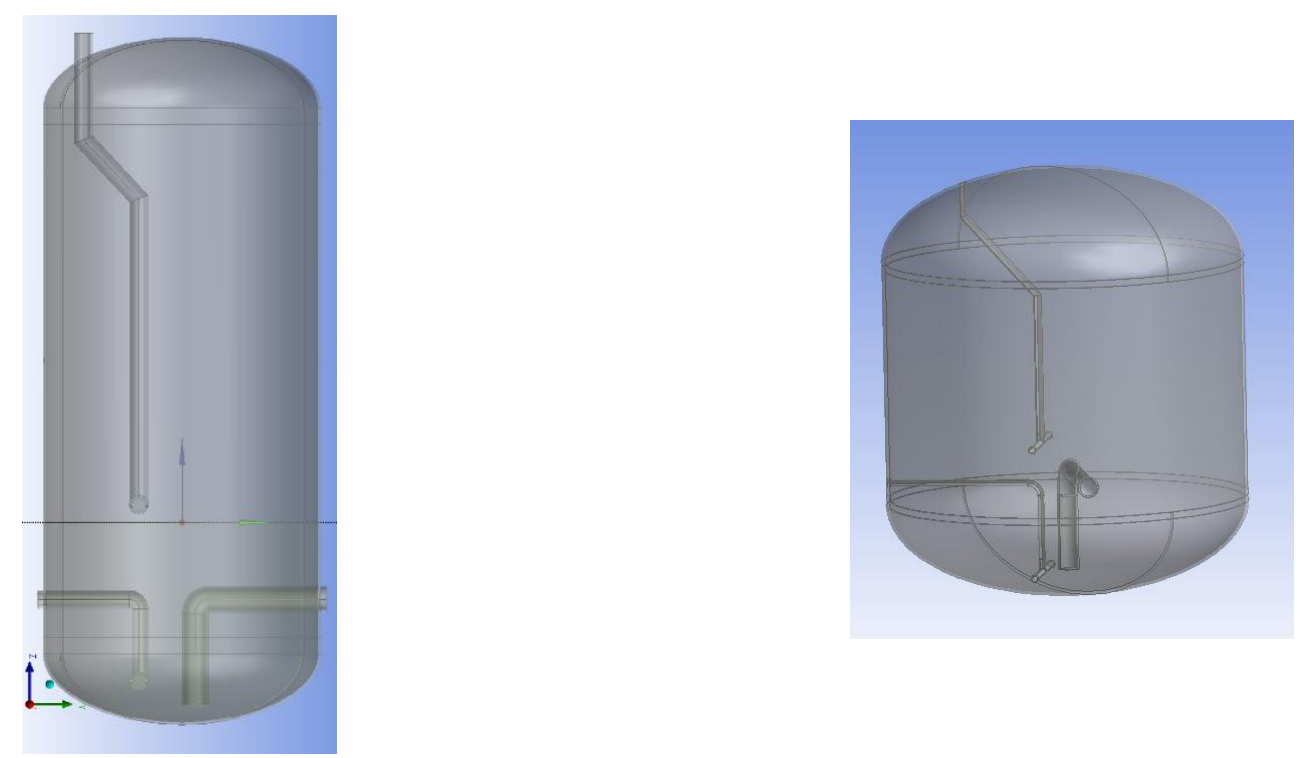

\section{FIG 1. THE IMAGE OF DRY POWDER TANKS $(170,3000 \mathrm{~kg})$}

\subsection{Calculation condition}

Before calculation, boundary condition was set as shown in Table 1. At first, type of fluid inlet was set as Pressure inlet and the value of the fluid pressure was set at 15.7 bar.abs. The properties of the powder are shown in Table 2

TABLE 1

CASES OF THE POWDER TANK

\begin{tabular}{|c|c|c|c|}
\hline & Powder Tank & Nozzle & Outlet \\
\hline Case 1 & $170 \mathrm{~kg}$ & 4 & None \\
\hline Case 2 & $170 \mathrm{~kg}$ & 8 & None \\
\hline Case 3 & $3000 \mathrm{~kg}$ & 4 & None \\
\hline Case 4 & $3000 \mathrm{~kg}$ & 8 & None \\
\hline
\end{tabular}

TABLE 2

PROPERTIES OF THE POWDER

\begin{tabular}{|c|c|}
\hline Items & Requirements \\
\hline Main Components & Potassium Bicarbonate \\
\hline Type & Pure substance \\
\hline Group & Particle Solid \\
\hline Density & $0.95 \mathrm{~g} / \mathrm{cm}^{3}$ \\
\hline & $<40 \mu \mathrm{m}: 55 \%$ \\
Particle distribution & $40-63 \mu \mathrm{m}: 20 \pm 8 \%$ \\
& $63-125 \mu \mathrm{m}: 20 \pm 8 \%$ \\
\hline
\end{tabular}




\section{RESULT AND DISCUSSION}

\subsection{Result}

We set the points as shown in Figure 2 to confirm the activation of the powder. We set 10 points for $170 \mathrm{~kg}$ and 8 points for $3000 \mathrm{~kg}$. In this study, we proceed to analyze for 20 seconds to see that the powder is activated. And it was interpreted as a condition without outlet [6].
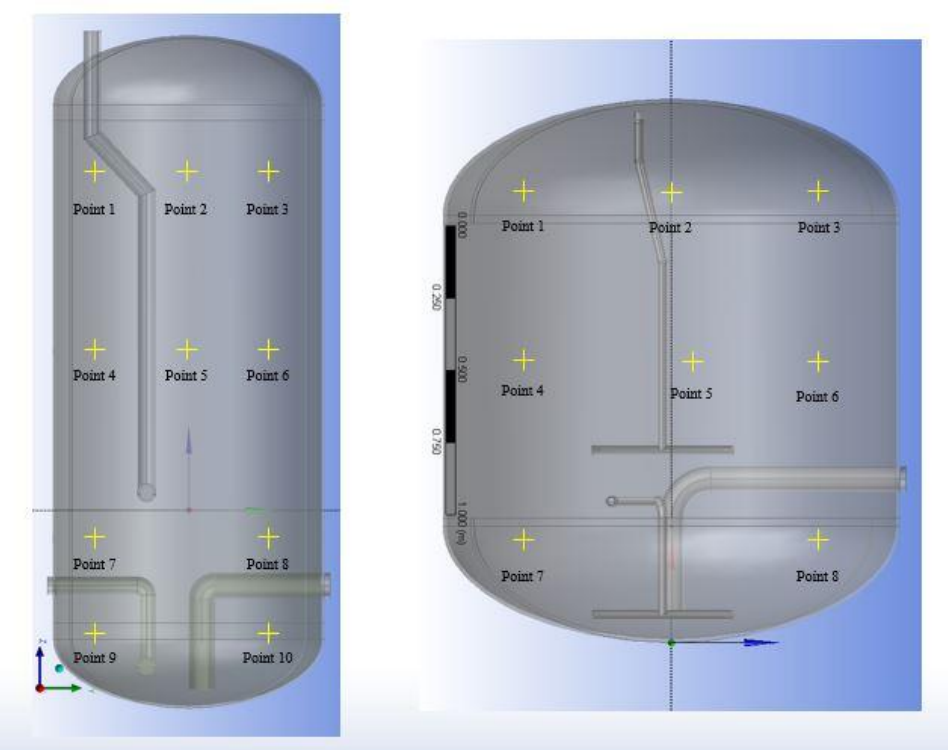

FIG 2. SET THE POINTS OF DRY POWDER TANK

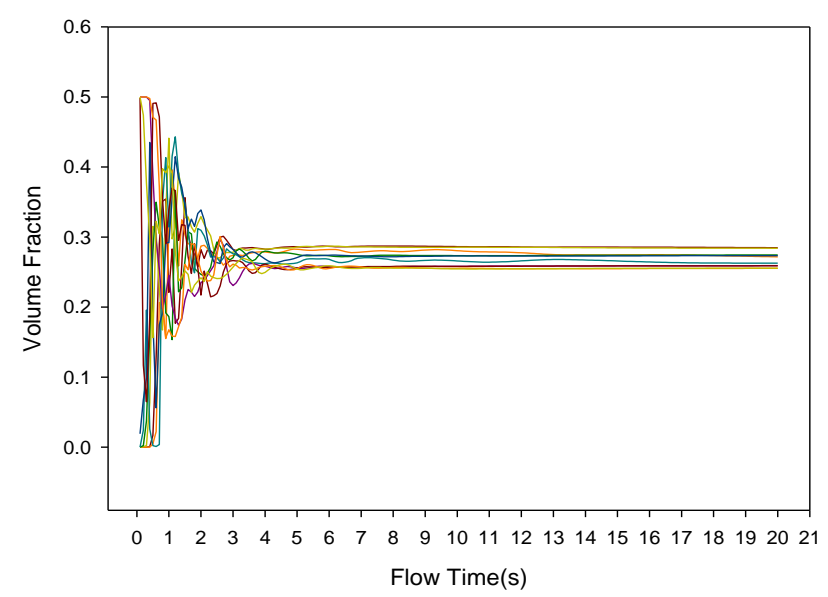

Fig 3. POWDER VOLUME FRACTION OF CASE 1

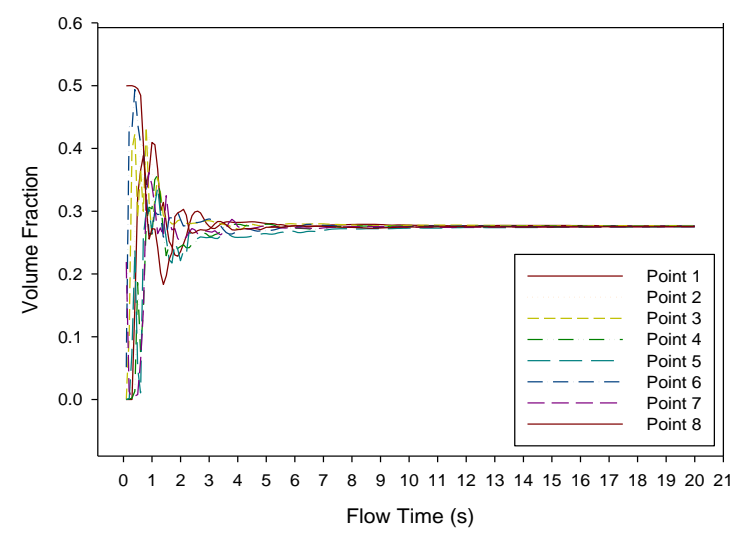

Fig 5. POWDER VOLUME FRACTION OF CASE 3

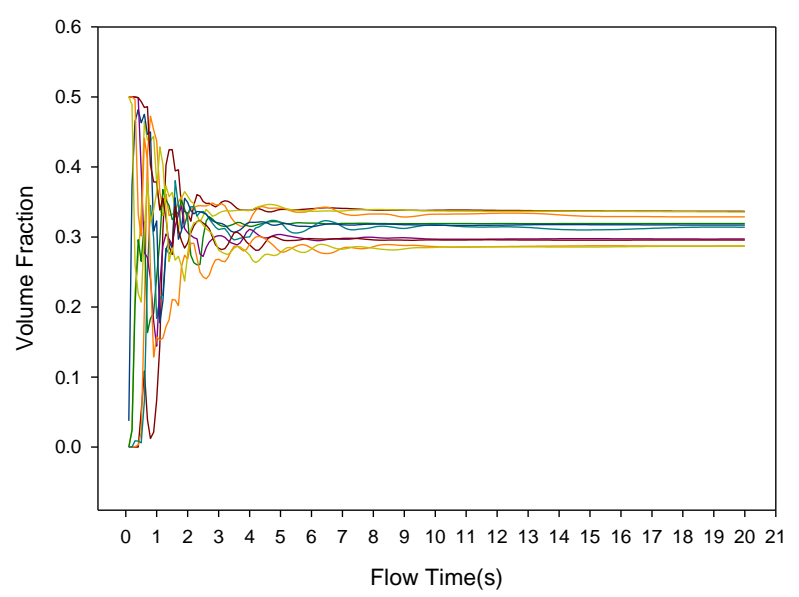

Fig 4. POWDER VOLUME FRACTION OF CASE 2

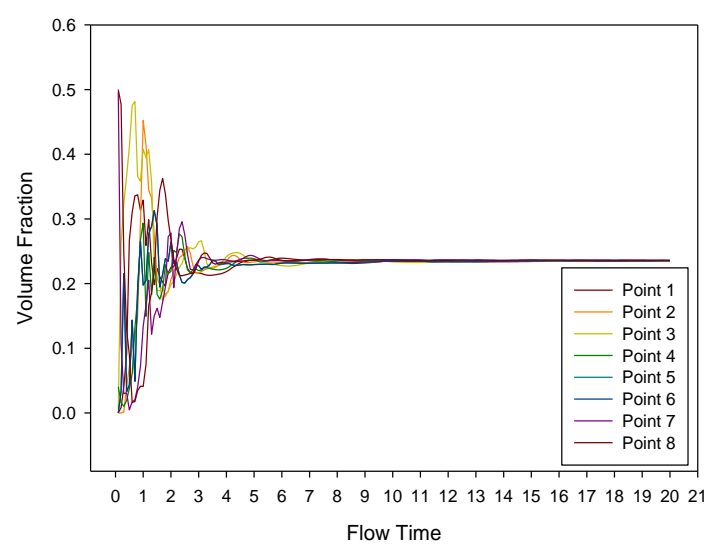

Fig 6. POWDER VOLUME FRACTION OF CASE 4 
Figure 3-6 shows the powder activation in case 1-4.

\subsection{Discussion}

When nitrogen gas was pressurized in a $170 \mathrm{~kg}$-Dry powder tank for 20 seconds, some mixing appeared but it was not completely mixed. In the $170 \mathrm{~kg}$-Dry powder tank, when the number of nozzles is 4 , the dispersion of powder is better.

It was confirmed that when the nitrogen gas was pressurized in the $3000 \mathrm{~kg}$-Dry powder tank for 20 seconds, the dispersion of powder was uniform. In the $3000 \mathrm{~kg}$-Dry powder tank, when the number of nozzles is 8, the dispersion of powder is better.

As a result, it was confirmed that the powder was well dispersed in case of $3000 \mathrm{~kg}$, but in case of $170 \mathrm{~kg}$, both cases showed insufficient activation. Therefore, we reanalyzed the powder to activate the $170 \mathrm{~kg}$ model. The value of the fluid pressure was set at 16.7, 17.7, 18.7 bar.abs (Table 3).

TABLE 3

CASES OF THE POWDER TANK

\begin{tabular}{|c|c|c|c|}
\hline & Powder Tank & Nozzle & Pressure (bar.abs) \\
\hline Case 5 & $170 \mathrm{~kg}$ & 4 & 16.7 \\
\hline Case 6 & $170 \mathrm{~kg}$ & 4 & 17.7 \\
\hline Case 7 & $170 \mathrm{~kg}$ & 4 & 18.7 \\
\hline Case 8 & $170 \mathrm{~kg}$ & 8 & 16.7 \\
\hline Case 9 & $170 \mathrm{~kg}$ & 8 & 17.7 \\
\hline Case 10 & $170 \mathrm{~kg}$ & 8 & 18.7 \\
\hline
\end{tabular}

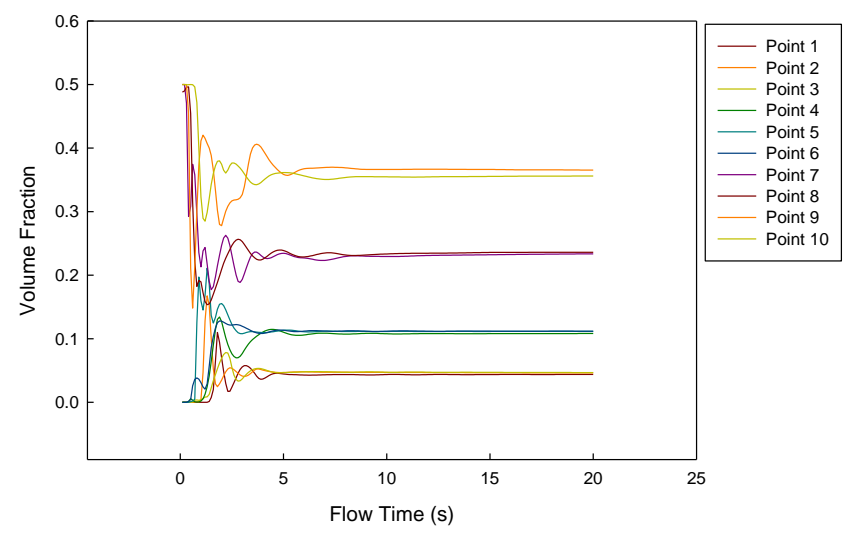

Fig 7. POWDER VOLUME FRACTION OF CASE 5

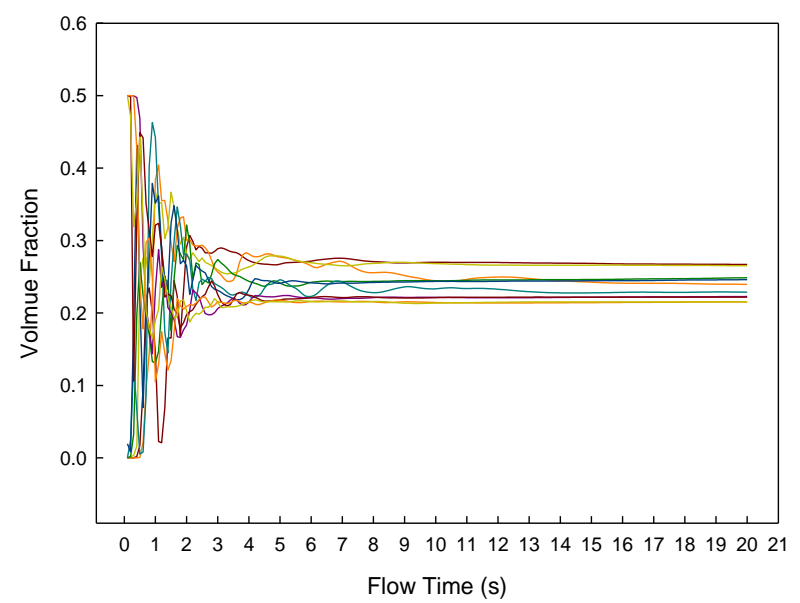

Fig 9. POWDER VOLUME FRACTION OF CASE 7

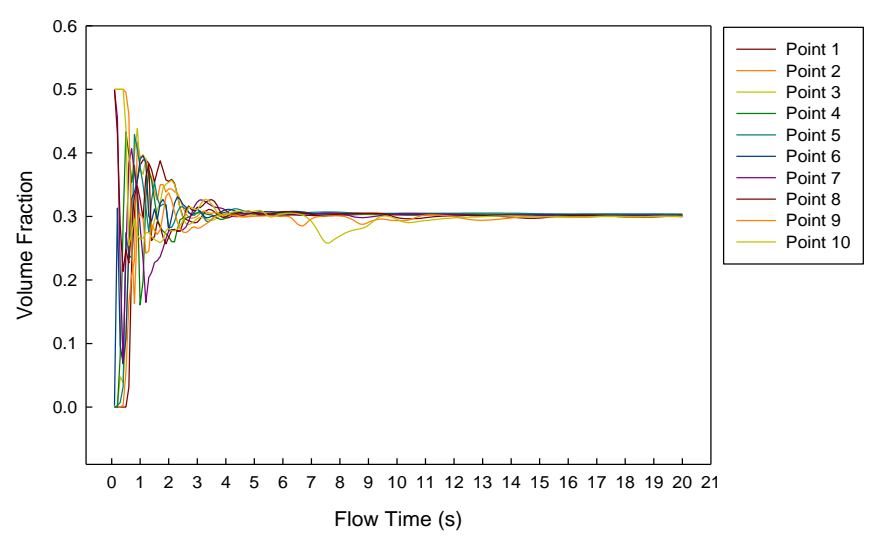

Fig 8. POWDER VOLUME FRACTION OF CASE 6

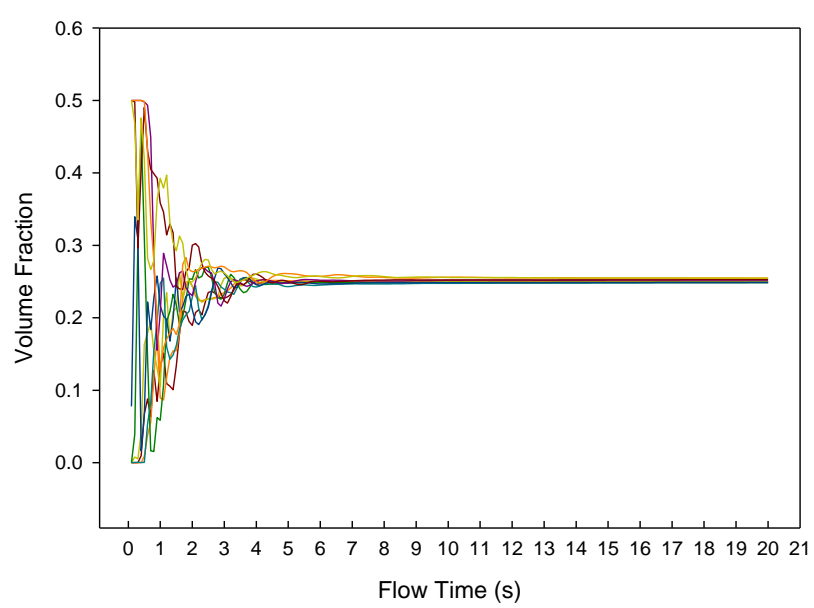

Fig 10. POWDER VOLUME FRACTION OF CASE 8 


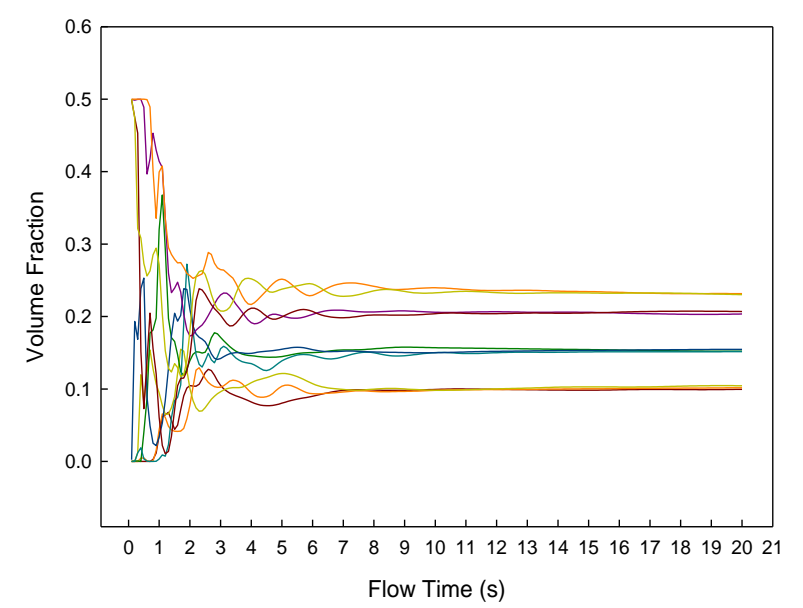

Fig 11. POWder VOLUMe fRaCtion Of CASE 9

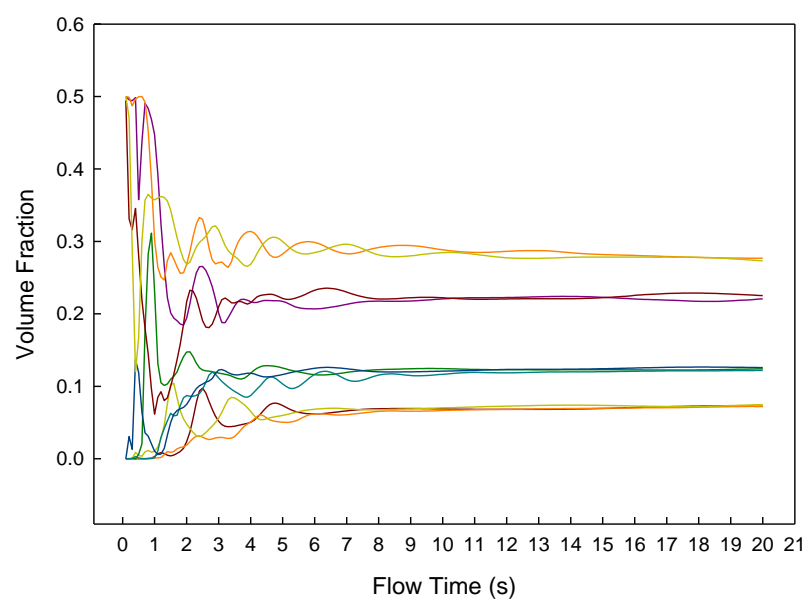

Fig 12. POWDER VOLUMe FRACTION OF CASE 10

As a result of analysis, it was confirmed that powder was activated at 17.7 bar.abs when the number of nozzles was 4 when more pressure was applied. When the number of nozzles was 8, the powder was activated well at 16.7 bar.abs. In the case of $170 \mathrm{~kg}$-Dry powder tank, the number of nozzles was 8 and the highest powder activation was observed at 16.7 bar.abs.

\section{CONCLUSION}

In this study, we investigated the activation of powders in dry powder tanks. The effect of the number of nozzles and pressure on the powder is summarized as follows. It was confirmed that when the nitrogen gas was pressurized in the $3000 \mathrm{~kg}$-Dry powder tank for 20 seconds, the dispersion of powder was uniform. In the 3000kg-Dry powder tank, when the number of nozzles is 8 , the dispersion of powder is better. In the case of $170 \mathrm{~kg}$ model, it was confirmed that there is a pressure to activate the powder according to the number of nozzles. When the number of nozzles was 4 and 8 , it was activated well at 17.7 bar and 16.7 bar. It was defined that the state of activation depends on the shape of powder tank of $170 \mathrm{~kg}$ and $3000 \mathrm{~kg}$. Therefore, the more the shape of the tank is closer to the ellipse, the better the activation is.

\section{ACKNOWLEDGEMENTS}

This research was supported by creative convergence R\&D of local main industry promotion business.

\section{REFERENCES}

[1] Dong-Suk Kim, "Development of fire extinguishing system suitable for unmanned engine room f a small ship", T. of Korean Institude of Fire Sci. \& Eng., Vol. 20, No. 3, 2006.

[2] Ha-Sung Kong and Jong-Jin Kim, "A study on improving extinguishing capacity of mobile water mist equipment”, Korea Safety Management\&Science, Vol. 11, No. 1, pp 15-26, 2009.

[3] K. W. Chu, B. Wang and A. B. Yu, "DISCRETE PARTICLE SIMULATION OF THE GAS-SOLID FLOW IN A CIRCULATING FLUIDIZED BED,” Engineering Conferences International, 2007.

[4] Chan-Young Cho, "Numerical Study on rotational flow and slurry dispersion in stirred tanks," unpublished.

[5] "Fluent User Guide," unpublished.

[6] Myeong-Rok Ryu and Kweon-Ha Park, "Hydrogen explosion effects at a containment building following a severe accident", Journal of the Korean Society of Marine Engineering, Vol. 40, No. 3 pp. 164 172, 2016. 